\title{
Dynamical Elastic Moduli of the Ti-13Nb-13Zr Biomaterial Alloy by Mechanical Spectroscopy
}

\author{
Odila Florêncio ${ }^{a}$, Javier Andres Muñoz Chaves ${ }^{\mathrm{a}}$, Paulo Sérgio da Silva Júnior, \\ Carlos Roberto Grandini ${ }^{\text {b }}$ Walter Libardi ${ }^{\circ *}$, Sandra Giacomin Schneider ${ }^{\mathrm{d}}$ \\ ${ }^{a}$ Departamento de Física, Universidade Federal de São Carlos - UFSCar, \\ CP 676, CEP 13565-905, São Carlos, SP, Brazil \\ ${ }^{\mathrm{b}}$ Departamento de Física, Universidade Estadual Paulista - UNESP, \\ CP 473, CEP 17033-360, Bauru, SP, Brazil \\ ${ }^{\circ}$ Departamento de Engenharia de Materiais, Universidade Federal de São Carlos - UFSCar, \\ CP 676, CEP 13565-905, São Carlos, SP, Brazil \\ ${ }^{\mathrm{d} D e p a r t a m e n t o ~ d e ~ E n g e n h a r i a ~ d e ~ M a t e r i a i s, ~ E s c o l a ~ d e ~ E n g e n h a r i a ~ d e ~ L o r e n a ~-~ E E L, ~}$ \\ Universidade de São Paulo - USP, CP 116, CEP 12602-810, Lorena, SP, Brazil
}

Received: January 19, 2012; Revised: May 31, 2012

\begin{abstract}
Dynamical Elastic Moduli of the Ti-13Nb-13Zr biomaterial alloy were obtained using the mechanical spectroscopy technique. The sample with heat treatment at $1170 \mathrm{~K}$ for 30 minutes and water quenched with subsequent aging treatment at $670 \mathrm{~K}$ for 3 hours (TNZ + WQ + 670 K/3 h), was characterized through decay of free oscillations of the sample in the flexural vibration mode. The spectra of anelastic relaxation (internal friction and frequency) in the temperature range from $300 \mathrm{~K}$ to $625 \mathrm{~K}$ not revealed the presence of relaxation process. As shown in the literature, the hcp structure usually does not exhibit any relaxation due to the symmetry of the sites in the crystalline lattice, but if there is some relaxation, this only occurs in special cases such as low concentration of zirconium or saturation of the stoichiometric ratio of oxygen for zirconium. Dynamical elastic modulus obtained for TNZ + WQ + $670 \mathrm{~K} / 3 \mathrm{~h}$ alloy was $87 \mathrm{GPa}$ at room temperature, which is higher than the value for Ti-13Nb-13Zr alloy ( $64 \mathrm{GPa}$ ) of the literature. This increment may be related to the change of the proportion of $\alpha$ and $\beta$ phases. Besides that, the presence of precipitates in the alloy after aging treatment hardens the material and reduces its ductility.
\end{abstract}

Keywords: $T i-13 \mathrm{Nb}-13 \mathrm{Zr}$, aging treatment, elastic modulus, anelastic relaxation

\section{Introduction}

Titanium and titanium alloys have a great clinical interest as biomaterials for use as materials for artificial implants (orthopedic or dental) for its high biocompatibility, excellent corrosion resistance and appropriate mechanical properties compared to stainless steels and alloys of $\mathrm{Co}-\mathrm{Cr}$. This alloys are distinguished by its low modulus of elasticity, closed to that of human bone (10-40 GPa), which ensure the adequate mechanical stress transfer to the surrounding bone ${ }^{1}$.

Nowadays the Ti-6Al-4V alloy is the major biomedical alloy used on orthopedic implants, but has a disadvantage because of its high modulus of elasticity (110 GPa), in addition that, recent studies revealed that the presence of $\mathrm{Al}$ and $\mathrm{V}$ ions are harmful to health in the long term implants ${ }^{2-4}$. Thus, among the new research of alloys for biomedical applications based in titanium free of toxic elements and with appropriate mechanical properties and high biocompatibility the Ti-13Nb-13Zr (TNZ) alloy appears as an option to be taken into account because the processing variables can be controlled to lead selected results ${ }^{4}$.

$\mathrm{Ti}-13 \mathrm{Nb}-13 \mathrm{Zr}$ alloy is typically an near- $\beta$ Ti alloy which, when heat treated up the $\beta$-transus temperature and

*e-mail: libardi@ufscar.br water-quenched posses a hexagonal $\alpha^{\prime}$-phase martensite microstructure, but followed by an aging treatment that is transformed into a martensite formed by $\alpha$-phase (hcp structure) with precipitates of $\beta$-phase (bcc structure) ${ }^{5-7}$.

In general it is of great interest to know in a metallic alloy the behavior of alloying elements and the mechanical properties, specifically the elastic modulus in biomaterials, therefore the mechanical spectroscopy becomes an important tool for characterization because it can provide information about the interaction of the matrix with the solutes atoms (substitutional and interstitial) ${ }^{8-11}$, besides dynamical elastic modulus (elastic modulus as function of temperature $)^{12}$ parameter of great importance from the viewpoint of biocompatibility.

This paper presents results of anelastic relaxation and elastic modulus as function of the temperature, obtained by mechanical spectroscopy from the flexural vibration of the fundamental mode of Ti-13Nb-13Zr alloy samples submitted to heat treatment of $1170 \mathrm{~K}$ for 30 minutes and water quenched with subsequent aging treatment to $670 \mathrm{~K}$ for 3 hours. 


\section{Experimental Part}

Starting from commercially pure materials $\mathrm{Ti}, \mathrm{Nb}, \mathrm{Zr}$, were obtained ingots of $18 \mathrm{~mm}$ diameter Ti-13Nb-13Zr alloy by arc melting in an atmosphere of argon. Then the ingots were subjected to cold swaging yielding rods of $6 \mathrm{~mm}$ diameter corresponding to $89 \%$ of plastic deformation. So, after of annealed at $1170 \mathrm{~K}$ for 30 minutes and water quenched, an aging treatment for 3 hours at a temperature of $670 \mathrm{~K}$ was performed in this sample, the sample was labeled as TNZ + WQ $+670 \mathrm{~K} / 3 \mathrm{~h}$. Crystalline phases and microstructure of the sample were characterized by X-ray diffraction (XRD) and scanning electron microscopy (SEM).

The ingots were cut into rectangular bar shape and additionally was performed successive etching in an acid solution of $2 \mathrm{~mL} \mathrm{HF}+10 \mathrm{~mL}$ HNO $3+8 \mathrm{~mL} \mathrm{H} 2 \mathrm{O}$ until get a bar with dimensions of $4.62 \times 20.66 \times 0.54 \mathrm{~mm}^{3}$ and free from impurities on the surface conditions appropriate for measurements of mechanical spectroscopy.

Anelastic relaxation spectra (Internal friction and frequency as function of the temperature) were obtained by the Acoustic Elastomer System (Vibran Technology ${ }^{\circledR}$, Model $\mathrm{AE}-102)^{13}$ in the temperature range of $300 \mathrm{~K}$ to $625 \mathrm{~K}$ with a heating rate of $1 \mathrm{~K} / \mathrm{min}$ and pressure of about $10^{-5}$ Torr.

Mechanical spectroscopy is a characterization technique which measures the absorbed energy (internal friction $\left(\mathrm{Q}^{-1}\right)$ ) by the solid when it is subjected to a mechanical oscillating stress with a certain frequency $(\omega)^{14}$. The internal friction is related to the anelastic strain suffered by the solid since the atomic rearrangement processes require a relaxation time to obtain a new state of equilibrium.

Since the stress and strain have a temporal dependence for real solid, from Hooke's Law the dynamical elastic modulus $(E)$ to an oscillating mechanics wave, can be written $^{12,14,15}$ :

$E(\omega)=\frac{\sigma^{*}}{\varepsilon^{*}}=E^{\prime}+i E^{\prime \prime}$ where $E$ ' and $E$ " represent the storage and loss dynamical elastic modulus. Thus from the tangent angle of lag $(\phi)$, corresponding to the difference between the imaginary and real parts of the dynamical elastic modulus, is possible determine the energy absorbed by the solid, or internal friction $\left(\mathrm{Q}^{-1}\right)$, besides, to flexural vibrations the internal friction $\left(Q^{-1}\right)$ can be obtained from the logarithmic decrement $(\gamma)$ of the free oscillations of the sample

$$
Q^{-1}(\omega, T)=\frac{E^{\prime \prime}}{E^{\prime}}=\tan (\varphi)=\frac{\gamma}{\pi}
$$

where logarithmic decrement $(\gamma)$.

In clamped free geometry, such as Acoustic Elastomer System the relation between resonant frequency of fundamental tone $\left(f_{1}\right)$ and dynamical elastic modulus $(\mathrm{E})$, can be written ${ }^{12}$ :

$$
f_{1}=0.1615 \frac{h}{l^{2}} \sqrt{\frac{E}{\rho}}
$$

where $h$ is thickness $l$ is the length and $\rho$ is the density of the sample.

\section{Results and Discussion}

Figure 1a shows the $X$ ray diffraction pattern of the sample TNZ + WQ + $670 \mathrm{~K} / 3 \mathrm{~h}$, where can be observed the presence of $\alpha$ and $\beta$ phases with structure hcp and bcc respectively, which are in agreement with the observed in the literature ${ }^{2,5,7}$ for this titanium alloy when submitted to aging treatment.

In the Figure $1 b$, the micrograph obtained by SEM revealed the presence of a matrix of $\alpha$-phase with a dispersion of $\beta$-phase precipitated, which is in agreement with XRD results.

Figure 2 shows the anelastic relaxation spectra, internal friction and oscillation frequency, as function of temperature for $\mathrm{TNZ}+\mathrm{WQ}+670 \mathrm{~K} / 3 \mathrm{~h}$ sample, where for the temperature range studied were not observed relaxation processes.

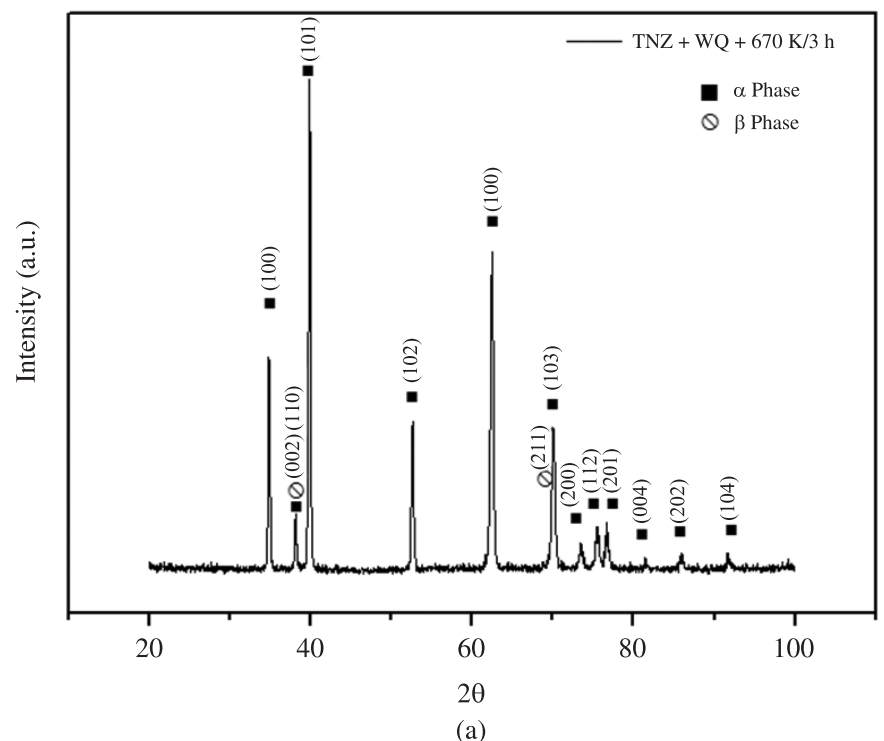

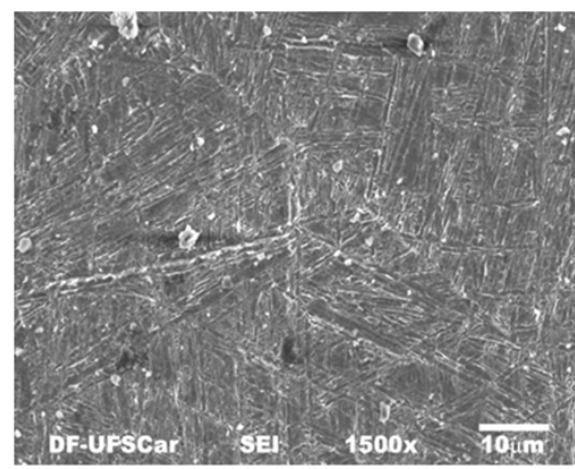

(b)

Figure 1. (a) DRX patterns and (b) SEM micrographs for TNZ + WQ + $670 \mathrm{~K} / 3 \mathrm{~h}$ sample. 

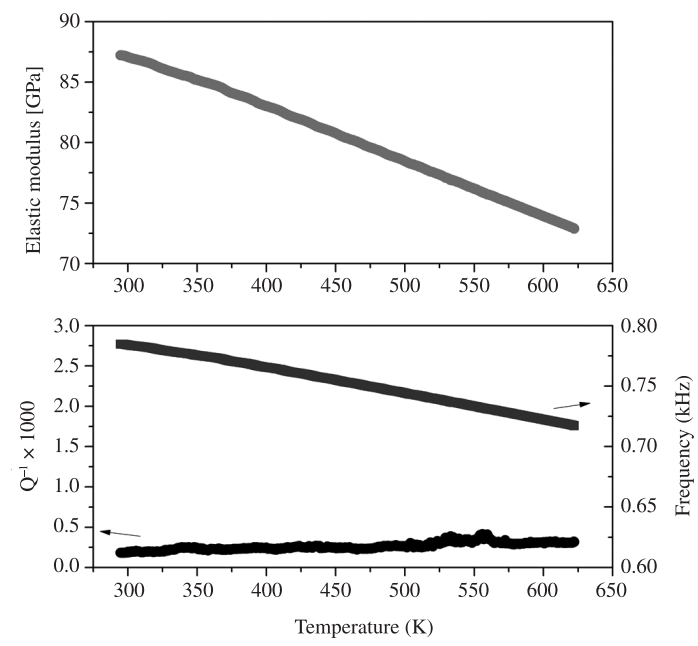

Figure 2. Anelastic relaxation spectra and dynamical elastic modulus for TNZ + WQ $+670 \mathrm{~K} / 3 \mathrm{~h}$ alloy.

The absence of relaxation processes can be associated in first instance, with the hcp structure presented by this alloy, since the interstitial sites, octahedral and tetrahedral, have tetragonal symmetry equal to those atoms in the lattice, so simple interstitial atoms do not produce anelastic relaxation ${ }^{11,16,17}$. Moreover in titanium alloys, like Ti-O-Me (Me being a metal such as $\mathrm{Zr}$ or $\mathrm{Nb}$ ), relaxation processes were found only from the individual atoms of oxygen trapped in the vicinity of substitutional atoms by the distortion that these last produce in the lattice. But in this case as the atomic radius of $\mathrm{Nb}$ and $\mathrm{Ti}$ are close the contribution to distortion of $\mathrm{Nb}$ element can be neglected. Concerning to $\mathrm{Zr}$, this contributes to the distortion of octahedral sites, but the increase of its contribution decreases the solubility of $\mathrm{O}$, so studies will revealed that only one relaxation peak is observed to a maximum concentration of $0.06 \%$ at. $\mathrm{Zr}$, then the peak intensity decreases ${ }^{18}$. Besides, it was observed by other researchers in alloys containing $\mathrm{Zr}$ as substitutional element and $\mathrm{O}$ as interstitial atom, that

\section{References}

1. Wong J and Bronzino J. Biomaterials. CRC Press. Taylor \& Francis Group; 2007.

2. Zhou YL, Niinomi M and Akahori T. Effects of Ta content on Young's modulus and tensile properties of binary Ti-Ta alloys for biomedical. Materials Science and Engineering A. 2004; 371:283-290 http://dx.doi.org/10.1016/j. msea.2003.12.011

3. Niinomi M. Mechanical properties of biomedical titanium alloys. Materials Science and Engineering A. 1998; 243:231-236. http://dx.doi.org/10.1016/S0921-5093(97)00806-X

4. Long HJRM. Review titanium alloys in total joint replacement - a Materials Science Perspective. Biomaterials. 1998; 19:1621-1639. http://dx.doi.org/10.1016/ S0142-9612(97)00146-4

5. Geetha M, Singh AK, Muraleedharan K and Gogia AK. Asokamani R. Effect of thermomechanical processing on the presence of substitutional elements affect the random distribution of the interstitial solute atoms in free solid solution and the anelastic relaxation process is observed only after the saturation of the stoichiometric ratio of $\mathrm{O}$ to $\mathrm{Zr}^{9,19,20}$.

The dynamical elastic modulus for TNZ +WQ $+670 \mathrm{~K} / 3 \mathrm{~h}$ sample was determined from flexural resonance frequency of fundamental tone of bar in clamped-free geometry using the Equation 3. The value of density of the alloy used in the equation was $4,767 \pm 0.006 \mathrm{~g} \cdot \mathrm{m}^{-3}$ obtained by the Arquimedes experimental method. Was observed a decrease in elastic modulus value for high temperature, as is typical in this kind of alloys. The value of dynamical elastic modulus at room temperature of TNZ $+\mathrm{WQ}+670 \mathrm{~K} / 3 \mathrm{~h}$ alloys obtained by flexural vibrations is $87 \mathrm{GPa}$. The difference between the values of dynamical elastic modulus observed in this work for Ti-13Nb-13Zr with aging treatment and literature data for Ti-13Nb-13Zr without aging treatment $(61.9 \mathrm{GPa})^{21}$, can be associated with the change of the proportion of $\alpha$ and $\beta$ phases which contributes atypically for elastic modulus value of the material, besides that, the presence precipitates in the alloy after aging treatment harden the material and reduce its ductility ${ }^{22,23}$.

\section{Conclusions}

Ti-13Nb-13Zr alloy subjected to heat treatment of the aging $670 \mathrm{~K} / 3 \mathrm{~h}$, shows no anelastic relaxation process due to interstitial or substitutional solutes. As was mentioned above, the hcp structure difficultly relaxes due to the symmetry of the sites in the lattice, besides, the relaxation that occurs will be only for special cases: low concentration of $\mathrm{Zr}(<0.06 \%$ at.) and saturation of the stoichiometric ratio of $\mathrm{O}$ for $\mathrm{Zr}$. Moreover, the module of elasticity is sensitive to aging treatment compared with data of the literature for this same alloy without aging treatment.

\section{Acknowlegdments}

The authors would like to thank to FAPESP, CNPq and CAPES for financial support. microstructure of a Ti-13Nb-13Zr alloy. Journal of Alloys and Compounds. 2001; 329:264-271. http://dx.doi.org/10.1016/ S0925-8388(01)01604-8

6. Mishra AK, Davidson JA, Kovacs P and Poggie RA. Ti-13Nb-13Zr: A new low modulus, high strenght, corrosion resistant near-beta alloy for orthopaedic implants. In: Beta Titanium Alloys in the 1990's. Warrendale: The Mineral, Metals and Marials Society; 1993. p. 61-72.

7. Kobayashi E, Doi H, Yoneyama T, Hamanaka H, Gibson IR, Best SM et al. Influence of aging heat treatment on mechanical properties of biomedical Ti-Zr based ternary alloys containing niobium. Journal of Materials Science: Materials in Medicine. 1998; 9:625-630. PMid:15348680. http://dx.doi. org/10.1023/A:1008927407556

8. Snoek JL. Letter to editor. Physica. 1939; 6(1):591-591. http:// dx.doi.org/10.1016/S0031-8914(39)90061-3

9. Bunn PM, Cummings DG and Leavenworth Junior HW. Effect of zirconium on internal friction in columbium. Journal of 
Applied Physics. 1962; 33(10):3009-3013. http://dx.doi. org/10.1063/1.1728554

10. Ahmad MS and Szkopiak ZC. Snoek relaxation peaks in solid solutions of niobium Journal of Physics and Chemistry of Solids. 1970; 31(8):17991804. http://dx.doi.org/10.1016/00223697(70)90170-8

11. Szkopiak ZC and Smith JT. Internal-friction of Nb-1 at per cent substitutional alloys. Journal of Physics D. 1975; 8(11):12731284. http://dx.doi.org/10.1088/0022-3727/8/11/006

12. Nowick AS and Berry BS. Anelastic Relaxation in Crystalline Solids. New York: Academic Press; 1972.

13. AE-102 Acoustic Elastometer. Vibran Technologies, Inc.

14. Schaller R, Fantozzi G and Gremaud G. Mechanical Spectroscopy Q-1 2001: with Applications to Materials Science. In: Proceedings of the Summer School Q-1; 2001; Switzerland. Switzerland: Trans Tech Publications LTD. v. $366-368$.

15. Lanter MS, Golovin IS, Neuhäuser H and Sinning HR. Internal friction in metallic materials: A handbook. Berlin Heidelberg: Springer-Verlag; 2007. Series in Materials Science.

16. Povolo $F$ and Bisogni EA. Mechanical relaxation modes of paired point defects in hep crystals. Acta Metallurgica. 1966; 14:711-718. http://dx.doi. org/10.1016/0001-6160(66)90118-0
17. Asundi MK and Rao CN. Internal friction in hexagonal metals. Bulletin of Materials Science. 1984; 6(5):959-969. http:// dx.doi.org/10.1007/BF02821422

18. Guptat $\mathrm{D}$ and Weinigt $\mathrm{S}$. Interactions between interstitial and substitutional solutes in an hcp laticce. Acta Metallurgica. 1962; 10:292-298. http://dx.doi. org/10.1016/0001-6160(62)90005-6

19. Botta FWJ, Florêncio O, Grandini CR, Tejima H and Jordão JAR. Mechanical multiple relaxation spectra in $\mathrm{Nb}-\mathrm{Zr}-\mathrm{O}$ alloys. Acta Metallurgica et Materialia. 1990; 38(3):391-396. http:// dx.doi.org/10.1016/0956-7151(90)90143-5

20. Florêncio O, Silva Junior PS, Stefanini TF and Botta WJ. Influence of oxygen on the damping properties of $\mathrm{Nb}-\mathrm{Zr}$ alloys. Key Enginnering Materials. 2006; 319:121-126. http://dx.doi. org/10.4028/www.scientific.net/KEM.319.121

21. Schneider S, Schneider SG, Silva HM and Neto CM. Study of the non-linear stress-strain behavior in Ti-Nb-Zr alloys. Materials Research. 2005; 8(4):435-438. http://dx.doi. org/10.1590/S1516-14392005000400013

22. Cáceres D, Munuera C, Ocal C, Jiménez JA, Gutiérrez A and López MF. Nanomechanical properties of surface-modified titanium alloys for biomedical applications. Acta Biomaterialia. 2008; 4(5):1545-1552. PMid:18499544. http:// dx.doi.org/10.1016/j.actbio.2008.04.009

23. Schneider SG. Obtenção e caracterização da liga Ti-13Nb-13Zr para aplicação como biomaterial. [Tese]. São Paulo: Universidade de São Paulo; 2001. 